Journal of Applied Pharmaceutical Science Vol. 6 (07), pp. 085-093, July, 2016

Available online at http://www.japsonline.com

DOI: $10.7324 / \mathrm{JAPS} .2016 .60713$

ISSN 2231-3354 (cc) BY-NC-SA

\title{
Development of PVC membranes with clove oil as plasticizer for blood bag applications
}

\author{
Ahmed M. Omer ${ }^{1}$, T. M. Tamer ${ }^{1 *}$, Abd EL Monem ${ }^{2}$, Sami Abd Elmoaty ${ }^{2}$, Mona Abd El Fatah², Gamal R Saad ${ }^{3}$ \\ ${ }^{1}$ Polymer materials research department, Advanced Technologies and New Materials Research Institute (ATNMRI), City of Scientific Research and \\ Technological Applications (SRTA-City), New Borg El-Arab City, P.O. Box: 21934 Alexandria, Egypt. ${ }^{2}$ National Organizations for Drug Control and \\ Research, Cairo, Egypt. ${ }^{3}$ Faculty of Science, Cairo University, Giza. Egypt.
}

\begin{tabular}{l} 
ARTICLE INFO \\
\hline Article history: \\
Received on: $25 / 04 / 2016$ \\
Revised on: $15 / 05 / 2016$ \\
Accepted on: $30 / 06 / 2016$ \\
Available online: $28 / 07 / 2016$ \\
\hline Key words: \\
PVC, membranes, clove oil, \\
plasticizer, antibacterial.
\end{tabular}

\begin{abstract}
In the present study, Antimicrobial PVC films containing different amounts of clove oil as a plasticizer were prepared using traditional casting method. The physical and mechanical properties of the plasticized PVC membranes e.g. surface wettability were investigated. The increase of clove oil content demonstrated an increase in surface hydrophilicity and elongation to break the film. The thermogravimetric analysis revealed a decrease of polymer thermal stability by increasing clove oil concentration. The antibacterial activities against four different bacterial strains (two-gram positive: Staphylococcus aureus and Bacillus cereus \& two-gram negative: Pseudomonas aeruginosa and Escherichia coli) were promoted by addition of clove oil. Although the natural source of clove oil, the bio-evaluation of plasticized membranes showed an increase in hemolysis percent (\%) and thrombus weight. It can be concluded that the addition of clove to PVC need to further studies for applying in blood bags.
\end{abstract}

\section{INTRODUCTION}

Starting from the 17 th century, transfers of blood from healthy volunteer to patients was established as a medical treatment for some diseases and during a surgical operation (Greening et al., 2010). Until 1950, glass bottles were the most standard containers for blood transfusions and storage. Several problems were associated with using these old fashion vessels related to sterilizations, breakability, and the presence of air bubbles surround valves and during a blood transfusion (Ramsey and Schmidt, 2009; Duran, 1939). All of these reasons driving scientists to develop a new generation of flexible bags based on polymeric materials. Polyvinylchloride (PVC) plays an essential

\footnotetext{
* Corresponding Author
}

Dr.Tamer Mahmoud Tamer Abdelrazik,Email: ttamer85@gmail.com; Correspondence Address: Polymer materials research department, Advanced Technologies and New Materials Research Institute, City of Scientific Research and Technological Applications (SRTA-City), New Borg El-Arab City, P.O. Box: 21934 Alexandria, Egypt. role in modern design bags, due to its inertness, durability, and resistance to heat/cold, chemicals, abrasion, and kinking (Rahman and Brazel, 2004). In common with virtually all plastics, PVC is composed of a polymerized organic substance, in this case, polymerized vinyl chloride, together with one or more additives that modify the characteristics of the polymer to optimize its suitability for a given application or process. Most usually, however, the best performance can be achieved when the material is made softer and more flexible. For this purpose, an additive described as a plasticizer is used, and the resulting plasticized, or soft, PVC finds widespread applications. A plasticizer can be defined as a material incorporated into the plastic to increase its flexibility (ASTM, 2012). A plasticizer used in plastic to confer softness to a polymer has to be a small molecular weight substance that actually acts as a molecular lubricant. Di-ethyl hexyl phthalate (DEHP) is the most common plasticizer for PVC-based medical devices such as tubings, intravenous bags, blood containers, and catheters. From 30-40 percent of blood bags use DEHP as plasticizer. 
DEHP can easily elute from PVC products into solutions that contact with the plastic and the migrated DEHP is directly and/or indirectly introduced into the human body (Allwod, 1986; Loff et al., 2000; Tickner et al., 2001). By 1967, Guess reported that DEHP leached from the plastic blood bags into plasma (Guess et al., 1967). Later, Jaeger and Rubin detected DEHP that present at levels of 50-70 mg/l (Jaeger and Rubin, 1970). The release of DEHP depends on some factors, covering the lipids content in the blood, the storage time and the temperature. DEHP is ranked as a reproductive toxin.

Self-disinfected PVC membranes to be used in biomedical take attention of scientists in last decay. Several approaches were done to achieve this goal. Including grafting of PVC surfaces with biocidal molecules to prevent bacterial growth on the surface. Indeed, antibacterial PVC surfaces were successfully prepared by grafting of Heparin (Zhou and Meyerhoff, 2005), Chitosan (Asadinezhad et al., 2010; Mao et al., 2004; Mohyeldin et al., 2015a), PEG (Balakrishnana et al., 2005), silver nitrate (Balazs et al., 2004), aromatic thiol compounds (Herrero et al., 2006).

Today the modern studies awarded to increase antimicrobial and haemocompatibility of the native polymer besides improving mechanical and physical properties of the polymer itself without adding any hazard materials (Omer et al., 2016).

Natural products such as plant essential oils (EOs) have used in human health such as functional food, food additives, medicine, nutritional supplements and cosmetic manufacturing. Essential oils also called volatile oils, are aromatic oily liquids obtained from plant materials such as flowers, buds, seeds, leaves, twigs, bark, herbs, wood, fruits, and roots. Plant EOs have antimicrobial, antioxidant and antimutagenic activities, and potentially beneficial effects on certain health conditions (BURT 2004). The antimicrobial activity of essential oils is due to some small terpenoids and phenol compounds (Oussalah et al., 2006). Several of these are classified as generally recognized as safe (Sharififar et al., 2007). Essential oils such as tea tree oil, lavender oil, thyme oil, peppermint oil and eugenol oil have been traditionally used by people for various purposes in different parts of the world.

The aim of the work is to plasticize PVC with eugenol that considered the main component of clove oil instead of synthetic plasticizer DEHP to be used in blood bag applications.

\section{MATERIALS AND METHODS}

\section{Materials}

Polyvinyl chloride (M. wt. $\sim 48 \times 10^{4} \mathrm{Da}$ ), fine powder was purchased from Belami fine chemicals, (India). Tetrahydrofuran (THF) (Purity 99.9\%) was purchased from sisco research laboratories (India). Clove oil \& Sodium chloride (Purity 99.5\%). International co for Supp \& Med. Industries, (Egypt). Monosodium phosphate \& Disodium phosphate (Purity $98 \%$, Sigma-Aldrich, Germany). Were purchased from sigm-aldrich,
Germany), Yeast Extract bacteriological grade, Biobasic Inc. (Canda). Peptone powder bacteriological grade, Biobasic Inc. (Canda).

\section{Bacteria}

Four bacterial strains were used for evaluating the antibacterial activity of plasticized PVC membranes. These were included two Gram-negative strains (E. coli and P. aeruginosa) and two Gram-positive ( $S$. aureus and B. cereus). All bacteria were provided from Genetic Engineering and Biotechnology Research Institute (GEBRI), City of Scientific Research and Technological Applications (SRTA-City). The strains were refreshed through inoculating in LB broth (peptone $1 \%$, yeast extract $0.5 \%, \mathrm{NaCl} 1 \%$, and $\mathrm{pH} 7 \pm 0.2$ ) and they were incubated overnight at $37^{\circ} \mathrm{C}$ and $150 \mathrm{rpm}$ in a rotary shaker.

\section{Methods \\ Preparation of PVC membranes}

The plasticized PVC membranes were prepared by using traditional casting method. PVC (1 g) was dissolved in $25 \mathrm{ml}$ THF at room temperature. A predetermined amount of clove oil was added to the solution under stirring to obtain a homogenous solution. On a clean glass petri dish, the solution was cast at room temperature for $48 \mathrm{hrs}$ to ensure complete solvent evaporation. Once the membrane was dried and separated from the Petri dish, it was rinsed with $50 \mathrm{ml}$ of distilled water. The wet membranes were spread out and allowed to dry under vacuum for $24 \mathrm{hrs}$ at room temperature. Six different plasticized PVC membranes with clove oil were studied and coded as sample PVC-0, PVC-C 0.1, PVC- C 0.2, PVC- C 0.3, PVC- C 0.4 and PVC- C 0.5 containing different amounts of clove oil $0,0.1,0.2,0.3,0.4$ and $0.5 \mathrm{Wt} \%$ respectively.

\section{UV-Vis Spectroscopic analysis}

The electronic absorbance of plasticized PVC membranes was done using spectrophotometer (Model Ultrospec 2000 made in England) scanned from $190-1000 \mathrm{~nm}$.

\section{Infrared spectroscopic analysis (FT-IR)}

The structure of plasticized PVC membranes was investigated by Fourier Transform Infrared Spectrophotometer (Shimadzu FTIR - 8400 S, Japan).

\section{Thermogravimetric analysis (TGA)}

Thermal analysis of plasticized PVC membranes was carried out using Thermal Gravimetric Analyzer (Shimadzu TGA -50 , Japan). The thermograms were performed from ambient temperature to $600{ }^{\circ} \mathrm{C}$ at heating rate $10{ }^{\circ} \mathrm{C} / \mathrm{min}$ under Nitrogen gas with flow rate $20 \mathrm{ml} / \mathrm{min}$.

\section{Scanning electron microscope (SEM)}

Scanning of plasticized PVC membranes were carried out using Scanning Electron Microscope (Joel Jsm 6360LA, Japan). 


\section{Tensile testing}

Universal tensile test were performed in an AG-1S, SHIMADZU universal testing machine, according to ASTM D882 standards for testing tensile properties of paper and paper broad using a constant rate of elongation apparatus. Membrane thickness measurements were determined with an electronic digital micrometer.

\section{Contact angle measurements}

Static water contact angle measurements were performed at room temperature using (advanced Gonimeter model 500-F1) in a sessile drop configuration (using ultrapure water as the liquid), coupled with a video camera and image analysis software. At least, ten droplet images were obtained for each film (Mohyeldin et al., 2015b).

\section{Surface roughness}

The surface roughness of the substrate used for blood contact materials is critical. The average roughness was measured using surface roughness tester SJ- 201P, Japan. Samples were mounted on a glass slide with a double-sided tap. Minimum sample dimensions were $25 \mathrm{~mm}$ x $25 \mathrm{~mm}$. All results are the average of triplicate measurements (Mohy Eldin et al., 2008).

\section{Optical properties}

Film color was measured by an X-Rite Model Sp64 Made in USA. The colorimeter was calibrated with white and black plates. A white standard color plate for the instrument calibration was used as a background for color measurements of the films. The system provides the values of three color components; L* (black-white component, luminosity), and the chromaticness coordinates, $\mathbf{a}^{*}$ (+red to -green component) and $\mathbf{b}^{*}$ (+yellow to - blue component). Color differences $\Delta \mathbf{E}^{*}$ were also calculated by the following equation:

$\Delta \mathrm{E}=\Delta \mathrm{a}^{*}+\Delta \mathrm{b}^{*}+\Delta \mathrm{L} *$

$$
\Delta E=\sqrt{\Delta a^{*}+\Delta b^{*}+\Delta L^{*}}
$$

Where; $\Delta \mathrm{L} *=\mathrm{L} *-\mathrm{L} 0 *, \Delta \mathrm{a} *=\mathrm{a} *-\mathrm{a} 0 *, \Delta \mathrm{b} *=\mathrm{b} *-\mathrm{b} 0 *$

$\mathbf{L} * \mathbf{0} ; \mathbf{a} * \mathbf{0} ; \mathbf{b} * \mathbf{0}$ are the color parameter values of the standard and $\mathbf{L}^{*} ; \mathbf{a}^{*} ; \mathbf{b}^{*}$ the color parameter values of the sample.

\section{Antibacterial assay}

\section{Broth evaluation method}

Antimicrobial activity of plasticized PVC membranes was measured according to the reported method previously (Skyttä and Mattila., 1991). Briefly, the bacteria were inoculated in a Luria- Bertani medium (LB medium) containing (1\% peptone, $0.5 \%$ yeast extract, and $1 \% \mathrm{NaCl}$ ). The test tubes were incubated at $37^{\circ} \mathrm{C}$ for $24 \mathrm{hrs}$ with shaking. The obtained bacterial suspension was diluted with the same medium (100 fold). Then, $0.1 \mathrm{ml}$ of diluted bacteria suspension was cultured in a ten $\mathrm{ml}$ of $\mathrm{LB}$ medium, which contains a piece of membranes $(5 \mathrm{~cm} \mathrm{x} 1 \mathrm{~cm})$. The inoculated medium was maintained at $37^{\circ} \mathrm{C}$ and $150 \mathrm{rpm}$ for 24 hrs. The turbidity of bacteria was measured using UV-visible spectrophotometer at $620 \mathrm{~nm}$.

\section{Agar diffusion method}

Agar-well diffusion method was applied for screening the antibacterial activities of plasticized PVC membranes against E. coli, $P$. aeruginosa, Salmonella sp., S. aureus and B. cereus as described by the reported method (Castro et al., 2011). Briefly, 50 $\mu \mathrm{l}$ overnight cultures of the indicator microorganisms were swabbed on LB agar medium. Small discs of PVC membranes were placed on the agar surface. The plates were left in the refrigerator at $4{ }^{\circ} \mathrm{C}$ for $2 \mathrm{hrs}$ to allow diffusion of materials into the agar. The plates were incubated at $37^{\circ} \mathrm{C}$ for $24 \mathrm{hrs}$ then, they were investigated, and the bacterial inhibitions were photographed using gel documentation system.

\section{Evaluation of haemocompatibility}

The hemolysis tests were performed as described in American Society for Testing and Materials (ASTM) (ASTM F 756-00, 2000) (US Pharmacopeia XXIII., 1994; Hassan et al., 2010). Anticoagulated blood was used for this purpose. The tested samples were prepared by adding $1 \mathrm{ml}$ of anticoagulant acid citrate dextrose solution (ACD) to $9 \mathrm{ml}$ of fresh blood. Before performing the tests, Samples $\left(1 \mathrm{~cm}^{2}\right)$ were placed in polypropylene test tubes, and $7 \mathrm{ml}$ of phosphate buffer solution $\mathrm{pH} 7.0$ (PBS) were added. After $72 \mathrm{hrs}$ of incubation at $37^{\circ} \mathrm{C}$, the PBS was removed, and $1 \mathrm{ml}$ ACD blood $(9.02 \mathrm{mg} / \mathrm{ml})$ was added to each sample and maintained at $37^{\circ} \mathrm{C}$ for $3 \mathrm{hrs}$. Positive and negative controls were prepared by adding the same amount of ACD blood to $7 \mathrm{ml}$ of water and PBS, respectively. Each tube was gently inverted twice each 30 min to maintain contact with the blood with the material. After incubation, each fluid was transferred to a suitable tube and centrifuged at $2000 \mathrm{rpm}$ for $15 \mathrm{~min}$. The hemoglobin released by hemolysis was measured by the absorbance of the supernatants at $540 \mathrm{~nm}$ using a spectrophotometer (Model Ultrospec 2000). The percentage of hemolysis was calculated from the absorbance (A) as follows equation:

$$
\% \text { of haemolysis }=\frac{\text { Atest sample }-A(-) \text { control }}{A(+) \text { control }-A(-) \text { control }}
$$

According to ASTM F 756-00 (2000) materials can be classified into three different categories according to their haemolytic index (haemolysis \%): materials with percentages of haemolysis over 5\% are considered haemolytic; while the ones with haemolytic index between $5 \%$ and $2 \%$ are classified as slightly haemolytic. Finally, when the material presents a hemolysis percentage below $2 \%$, it is considered as a non-haemolytic material.

\section{Thrombogenicity}

Evaluation of thrombus formation on polymeric surfaces was carried out using a gravimetric method (Imai and Nose., 1972). Anticoagulated rabbit blood was used for this purpose. Anticoagulated was prepared by adding $1 \mathrm{ml}$ of anticoagulant acid citrate dextrose solution (ACD) and $9 \mathrm{~mL}$ of fresh rabbit blood. 
Before performing the tests, samples were immersed in PBS at a constant temperature of $37^{\circ} \mathrm{C}$. After $48 \mathrm{hrs}$ of incubation, the PBS was removed, and the ACD blood was put in contact with the surface of the membranes and also to an empty Petri dish, which acted as a positive control. Blood clotting tests were initiated by adding $0.02 \mathrm{ml}$ of a $10 \mathrm{M}$ calcium chloride solution and were stopped after $45 \mathrm{~min}$ by the addition of $5 \mathrm{ml}$ of water. Resultant clots were fixed with $5 \mathrm{ml}$ of a $36 \%$ formaldehyde solution and were then dried with tissue paper and finally weighed. At least three measurements were performed for each sample, and the mean values are reported (US Pharmacopeia XXIII., 1994).

\section{RESULTS AND DISCUSSION}

In the current research, PVC membranes were improved by utilized clove oil as a plasticizer. Changes of Physical and mechanical properties of membranes were studied beside its biological activates.

\section{Physical analysis \\ Water uptake}

Figure 1 represents the effect of clove oil content on the membranes water uptake. Obtained results show a neglected increase in water uptake. Hydrophobic character of clove oil prevents the adoption of water molecules to plasticized PVC membranes.

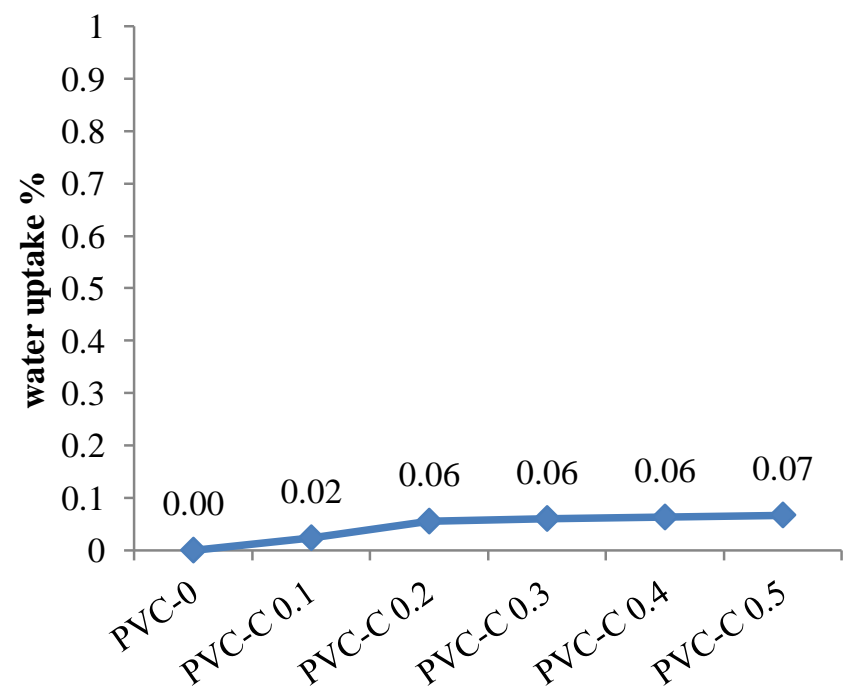

Fig. 1: water uptake PVC membranes plasticized with different contents of clove oil.

\section{Roughness}

It is well-known that some surface characteristics affect the extent of adhesion between two adjacent materials. One of such parameters is the surface roughness as surface asperities at the nanoscale level govern the overall adhesive forces. Figure 2 demonstrates an increase surface roughness by increased content of clove oil. That may be explained by the effect of plasticizer molecules in disruption of polymer chains during membranes casting (Chae et al., 2008; Brewer., 1984; Chapman et al., 2010).

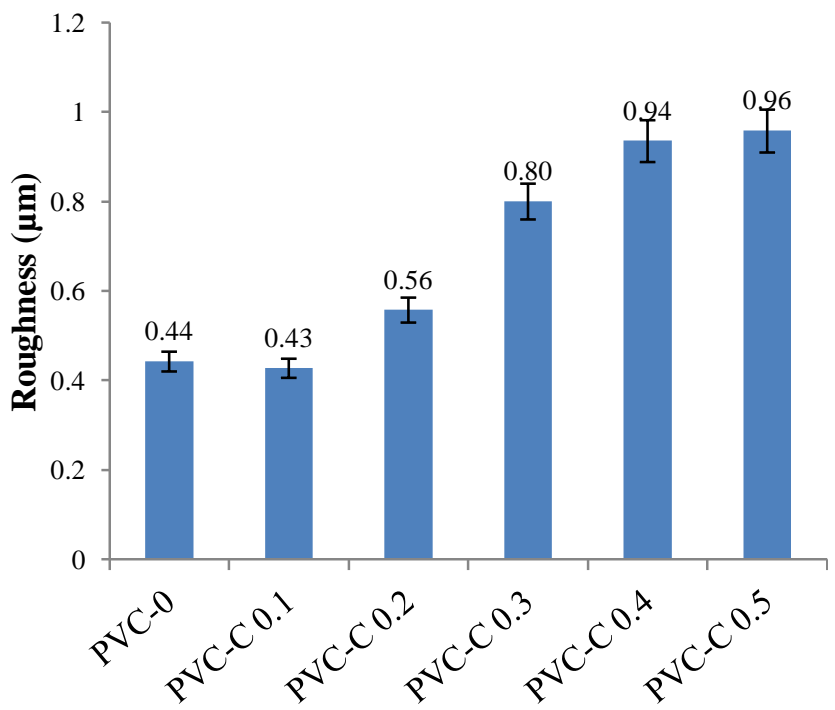

Fig. 2: Surface roughness of PVC membranes plasticized with different contents of clove oil.

\section{Wettability}

When the polymer materials come in contact with blood they can cause different undesired host responses like thrombosis, inflammatory reactions, and infections. The first event, which occurs, after exposure of biomaterials to blood, is the adsorption of blood proteins. Surface physicochemical properties of the materials as wettability greatly influence the amount and conformational changes of adsorbed proteins.

Figure 3 illustrates that increase of contact angle of PVC membranes plasticized with clove oil. These results suggest that clove oil enhancement hydrophobic nature and decrease wettability of PVC membranes.

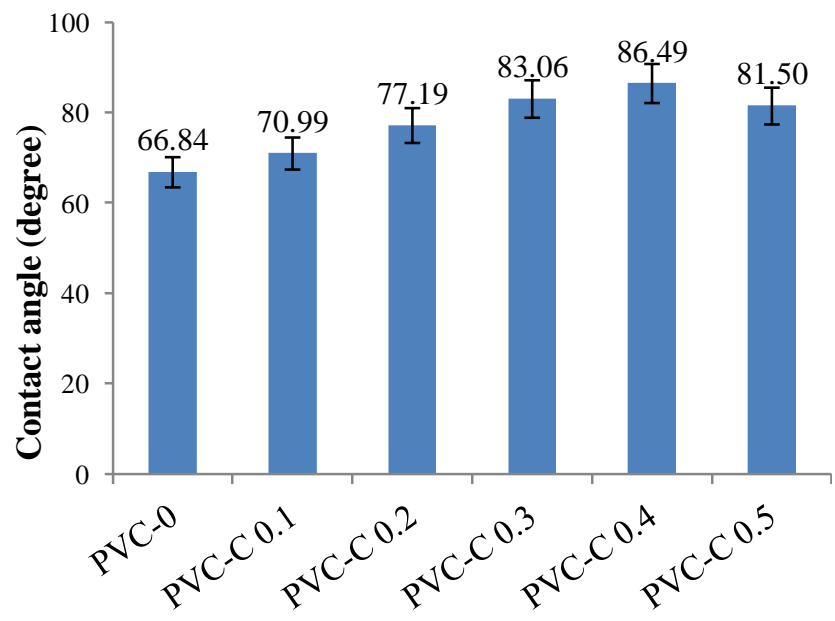

Fig. 3: contact angle measurements of PVC membranes plasticized with different contents of clove oil.

Wettability is believed to play an important role for the amount and the conformational changes of adsorbed proteins 
(Vroman and Adams, 1969; Norde and Lyklema, 1991). The hydrophobic interactions seem to be the dominant force driving protein adsorption/ unfolding on the surface (Norde and Lyklema., 1991). The hydrophobic interactions and their importance in protein adsorption were firstly indicated by studies showing that the protein adsorption increased with the decreasing wettability of the surface (Brash and Horbett, 1995) - so called "hydrophobic rule." The water structure is that which makes differences between hydrophobic and hydrophilic surfaces (Vogler, 1998). The interaction between a hydrophobic surface and a protein originates mainly from an entropy gain due to water desorption from the solid surface and from the protein molecule (Norde, 1986). In contrast water molecules near to a hydrophilic surface exhibit relatively more-dense water structure in an extended 3D network of self-associating molecules. This type of water structure is less reactive and. Therefore, it's hard to be removed (Norde and Lyklema, 1991). To hydrophilic surfaces, the proteins are adsorbed weakly with a conformation near to their native state. As a result the protein adsorption to hydrophilic substrata is generally reversible, whereas to hydrophobic one's it is not. Denaturation of the adsorbed protein by hydrophobic-hydrophobic interactions with the substrate can also contribute to an irreversible adsorption
(Chinn et al., 1992). As a result, the biological function of a given protein could be changed and altered, when it is adsorbed to a hydrophobic surface.

\section{Electronic spectra characterization \\ Color measurement}

The membranes color is necessary for consumer acceptance and general performance. Film color dimension ( $\mathrm{L}^{*}$, $\mathrm{a}^{*}$, and $\left.\mathrm{b}^{*}\right)$ and total color $(\Delta \mathrm{E})$ were measured using color hunter (X-Rite Model SP64). (See Table 1), Data obtained show a slight decrease in membrane brightness $\left(\Delta \mathrm{L}^{*}\right)$, and total color difference $\left(\Delta \mathrm{E}^{*}\right)$.

Table 1: Color values of plasticized PVC membranes with clove oil.

\begin{tabular}{ccccc}
\hline Sample code & $\Delta \mathbf{L}^{*}$ & $\Delta \mathbf{a}^{*}$ & $\Delta \mathbf{b}^{*}$ & $\Delta \mathbf{E}^{*}$ \\
\hline PVC-0 & 40.16 & -5.01 & -28.4 & 49.44 \\
PVC-C 0.1 & 39.8 & -4.98 & -23.9 & 46.69 \\
PVC-C 0.2 & 39.53 & -5.05 & -21.65 & 45.36 \\
PVC-C 0.3 & 39.65 & -4.7 & -21.2 & 45.2 \\
PVC-C 0.4 & 39.14 & -4.59 & -21.23 & 44.76 \\
PVC-C 0.5 & 38.98 & -4.43 & -14.04 & 41.67 \\
\hline
\end{tabular}

In the other hand, it demonstrates an increase in yellowish color of membranes.
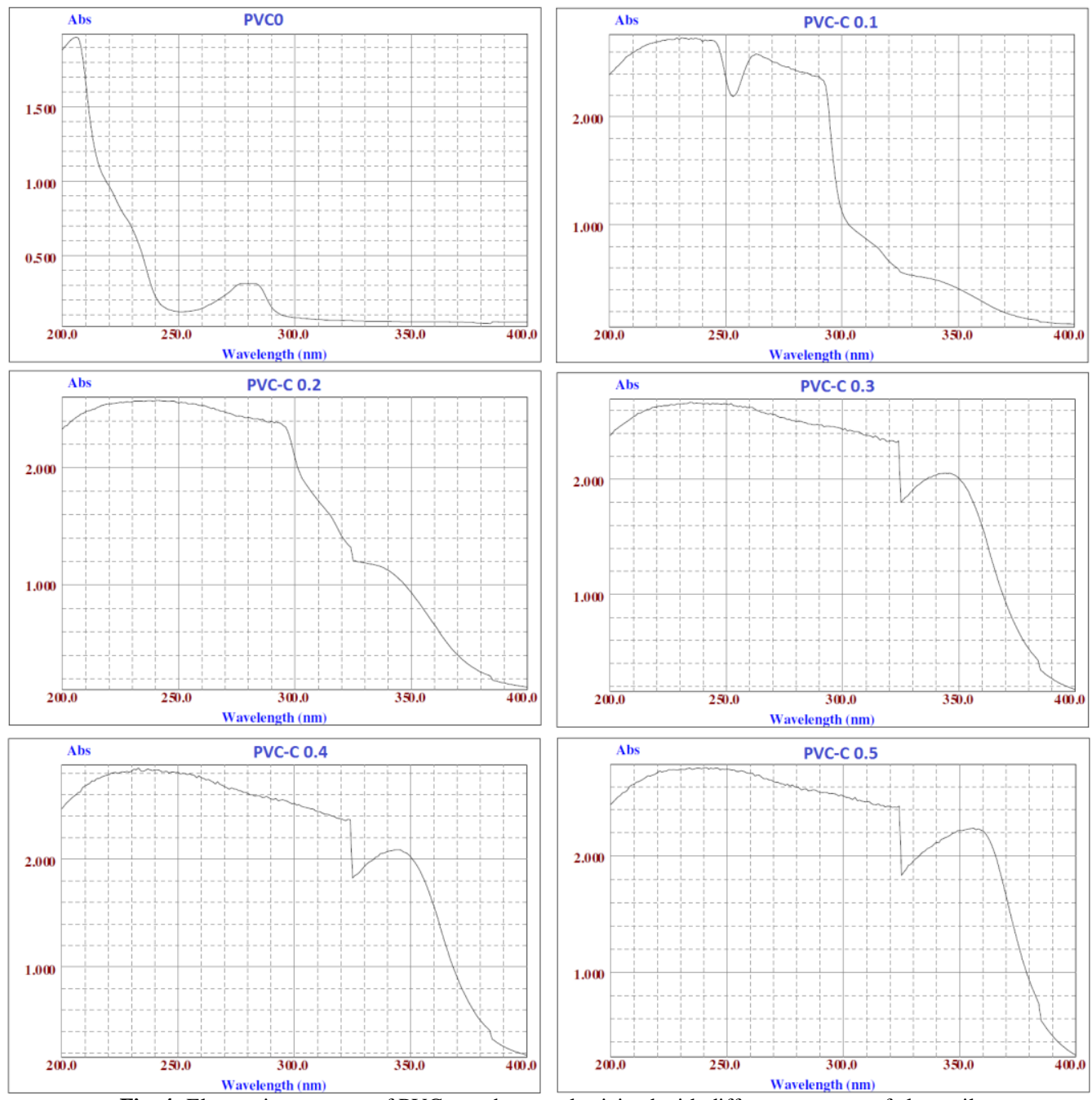

Fig. 4: Electronic spectrum of PVC membranes plasticized with different contents of clove oil. 


\section{UV-Vis Spectra}

Figure 4 shows the electronic absorption of membranes from 200 to $400 \mathrm{~nm}$. Collected charts demonstrate characteristic absorption peaks from $260-290 \mathrm{~nm}$ that may be attributed to the presence of the phenolic components in clove oil (i.e. Eugenol, $\beta$ caryophyllene). The increase of absorption bands and its shift to higher wavelength were attributed to increasing of clove oil content in membranes.

\section{FT-IR analysis}

Figure 5 illustrates FT-IR absorption of neat PVC and plasticized PVC membranes. Beside main characteristic peak of neat PVC membranes (C-H stretching mode observed at 2947 $\mathrm{cm}^{-1}, \mathrm{CH}_{2}$ deformation mode at $1340 \mathrm{~cm}^{-1}, \mathrm{C}-\mathrm{H}$ rocking mode at $1247 \mathrm{~cm}^{-1}$, trans $\mathrm{C}-\mathrm{H}$ wagging mode at $958 \mathrm{~cm}^{-1}, \mathrm{C}-\mathrm{Cl}$ stretching mode at $856 \mathrm{~cm}^{-1}$, and cis $\mathrm{C}-\mathrm{H}$ wagging mode at $619 \mathrm{~cm}^{-1}$ ), plasticized membranes exhibit a characteristic peaks phenolic components of clove oil $\left(\mathrm{OH}\right.$ phenolic at $3520 \mathrm{~cm}^{-1},=\mathrm{C}-\mathrm{H}$ stretching at $3060 \mathrm{~cm}^{-1}$ and aromatic $-\mathrm{C}=\mathrm{C}$ stretching at 1514 and $1616 \mathrm{~cm}^{-1}$ ). It was clearly seen that the intensity of these peaks with increase clove oil content.

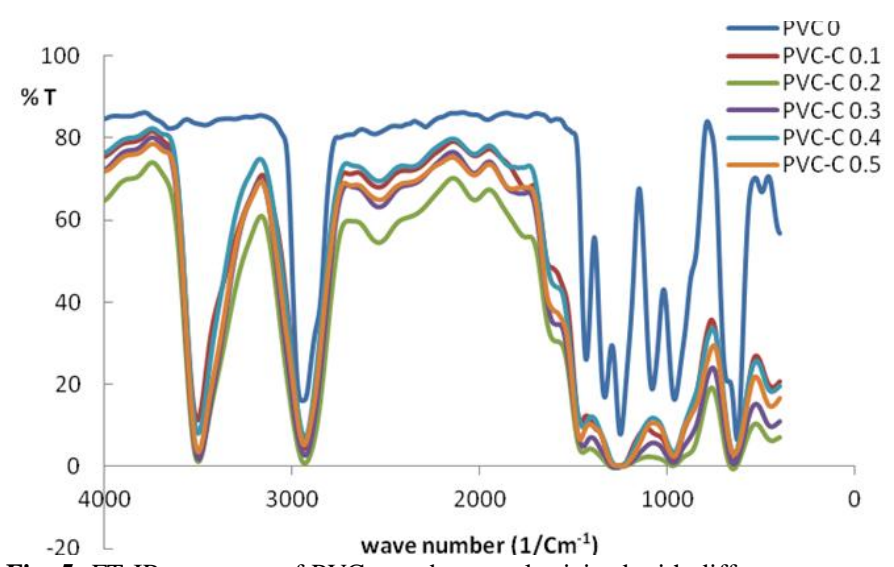

Fig. 5: FT-IR spectrum of PVC membranes plasticized with different contents of clove oil.

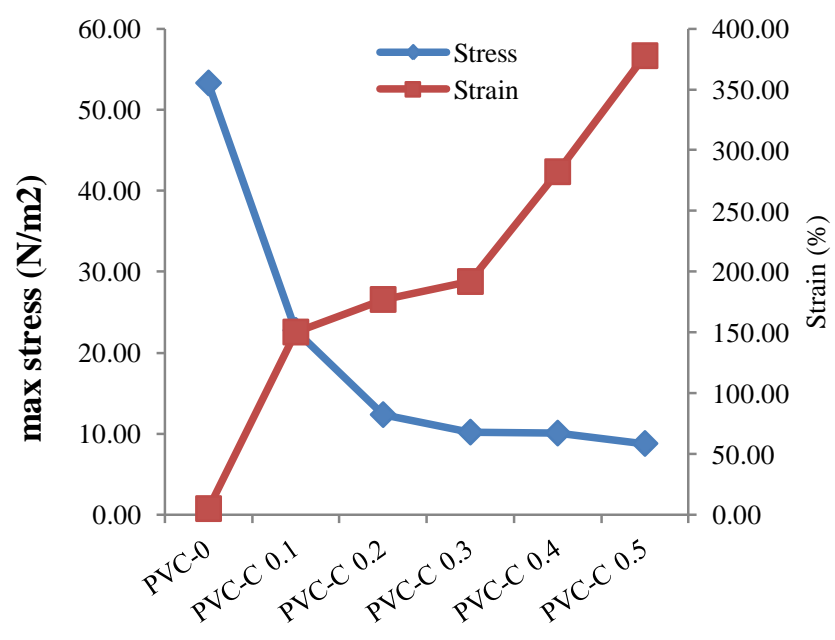

Fig. 6: stress strain parameters of neat $P V C$ and that plasticized with different amount of clove oil.

\section{Mechanical characterization}

Mechanical properties of plasticized PVC membranes with different amounts of eugenol were determined from critical breaking point of stretching. Maximum stress $\sigma_{\max }\left(\mathrm{Nm}^{-2}\right)$ was evaluated as the ratio of the stretching force divided by the crosssectional area of broken membrane piece. The maximum strain $\lambda_{\max }$ was measured as the elongation ratio of the initial length of the test piece. The result showed that the maximum stress decreases with increasing clove oil content (figure 6) While, the elongation percent was increased. This may be explained as a result of lubricant action of clove oil between PVC chains.

\section{Thermogravimetric analysis (TGA)}

Figure 7 illustrates thermograms of neat and plasticized PVC. As shown in figure 7 , the nest PVC exhibits two distinct stages. The first decomposition starts from $247^{\circ} \mathrm{C}$ to $305^{\circ} \mathrm{C}$ with a maximum decomposition temperature rate at $280^{\circ} \mathrm{C}$.

This stage of degradation is attributed to autocatalytic dehydrochlorination reaction (zipper elimination) with the subsequent formation of conjugated double bonds (Simon, 1990; 1992; Bacaloglu and Fisch, 1994; McNeill et al., 1995). After the loss of the first $\mathrm{HCl}$ molecule, the subsequent unsaturated structure formed in a PVC chain is an allylic chlorine structure. However, this allylic chlorine stimulates the next loss of an $\mathrm{HCl}$ molecule, and the repeated process leads to the chain or zip dehydrochlorination (Folarin and Sadiku, 2011). The second decomposition started from $450^{\circ} \mathrm{C}$, which presumably corresponds to the degradation of the resulting unsaturated hydrocarbons in the dehydrochlorination of PVC. The addition of clove oil generates a new weight loss in the temperature range 100-200 $\mathrm{C}$ due to evaporation of the volatile components of clove oil (Folarin and Sadiku, 2011).

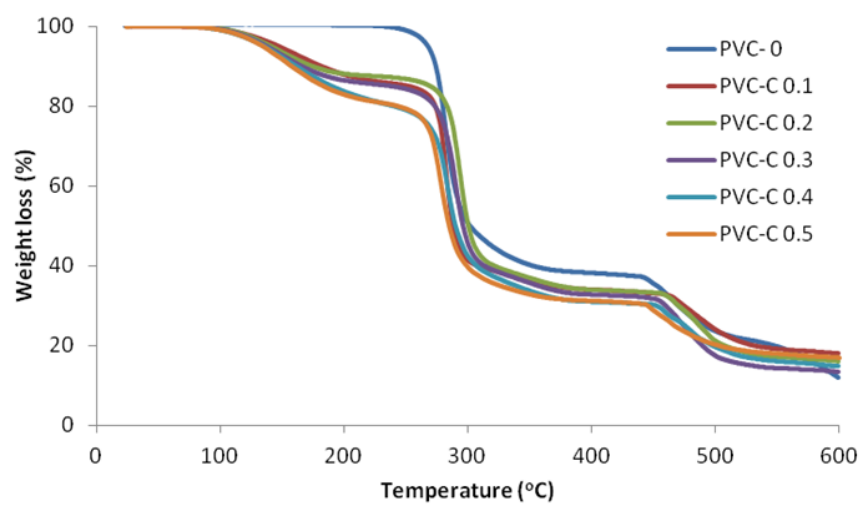

Fig. 7: TGA of neat PVC membranes compared with plasticized membranes with different amounts of clove oil.

\section{Membrane bio-evaluation \\ Antibacterial evaluation}

Inhibition activity of the neat and plasticized PVC membranes comparing to neat PVC membrane was tested against two-gram positive bacteria: $S$. aureus and B. cereus \& two-gram negative bacteria: $P$. aeruginosa and $E$. coli. The growths inhibition of the neat and plasticized PCV membranes is shown in 
figure 8. From figure 8 , we found that the plasticized PVC membranes exhibit a significant increase of inhibition zone by increasing the amount of clove oil. The digital photograph of antibacterial activity against tested microorganisms for different samples is shown in figure 9.

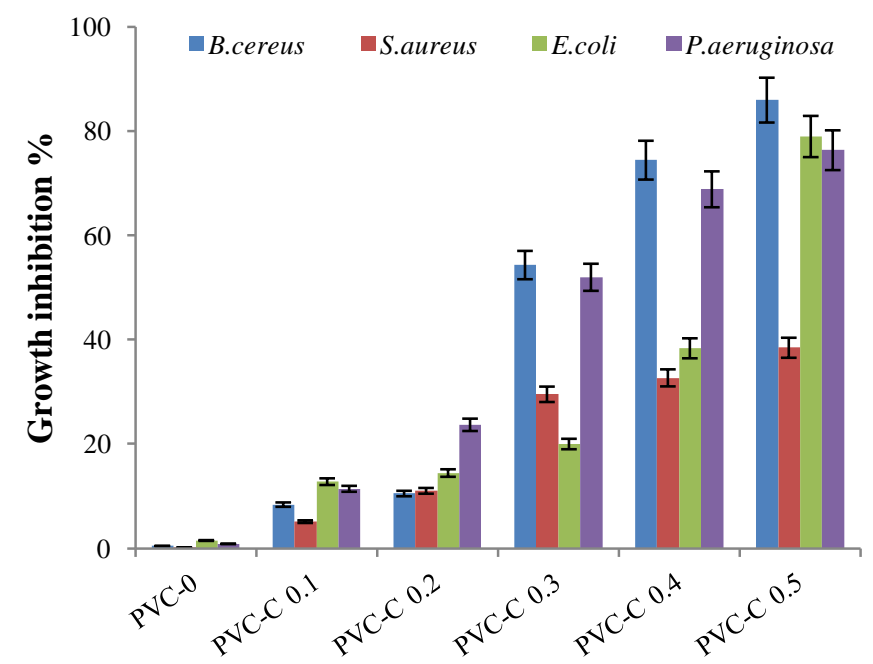

Fig. 8: Antibacterial activity of plasticized PVC membranes with different contents of clove oil against four different bacterial strains.

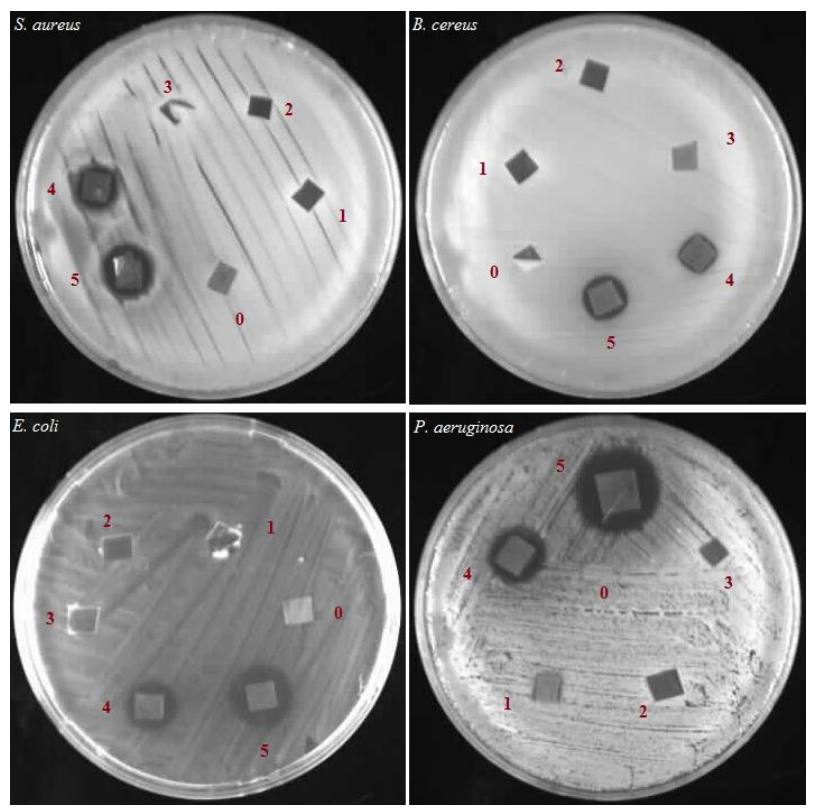

Fig. 9: Digital photograph of antibacterial activity of plasticized $\mathrm{PVC}$ membranes with different contents of clove oil $(\mathbf{0}=$ PVC-0, $\mathbf{1}=$ PVC-C $0.1,2=$ PVC- C 0.2, 3= PVC- C 0.3, 4= PVC- C 0.4 and 5= PVC- $\mathrm{C} 0.5$ ).

\section{Haemocompatibility}

Several essential requirements must be taken into consideration during preparation and qualification of medical devices, especially blood contact materials. Blood compatibility is recognized to play critical parameter during evaluation of wound dressing membranes. The value of haemolysis is taken as a mentor test. Figure 10 illustrates haemolysis percent of the prepared membranes. Haemolysis is regarded as an especially significant screening test. Once it provides quantification of small levels of plasma hemoglobin, which may not be measurable under in vivo conditions. As reported in the literature (ISO 10993-4(1999)), it is not possible to define a universal level of acceptable or unacceptable amounts of haemolysis. Although blood compatible materials should be nonhaemolytic, in practice several medical devices cause haemolysis. This means that when such haemolytic effect takes place, it is important to make sure that clinical benefits overcome these risks and that the values of haemolysis are within acceptable limits. According to ASTM F 756-00 (2000), materials can be classified into three different categories according to their haemolytic index (haemolysis \%): materials with percentages of haemolysis over than $5 \%$ are considered haemolytic; while the ones with haemolysis index between $5 \%$ and $2 \%$ are classified as slightly haemolytic. Finally, when material presents a haemolysis percentage below $2 \%$, it is considered as a nonhaemolytic material. Figure 11 shows a disastrous increase in haemolysis percent of blood contact at a high amount of clove oil (from 0.4$0.5 \%)$.

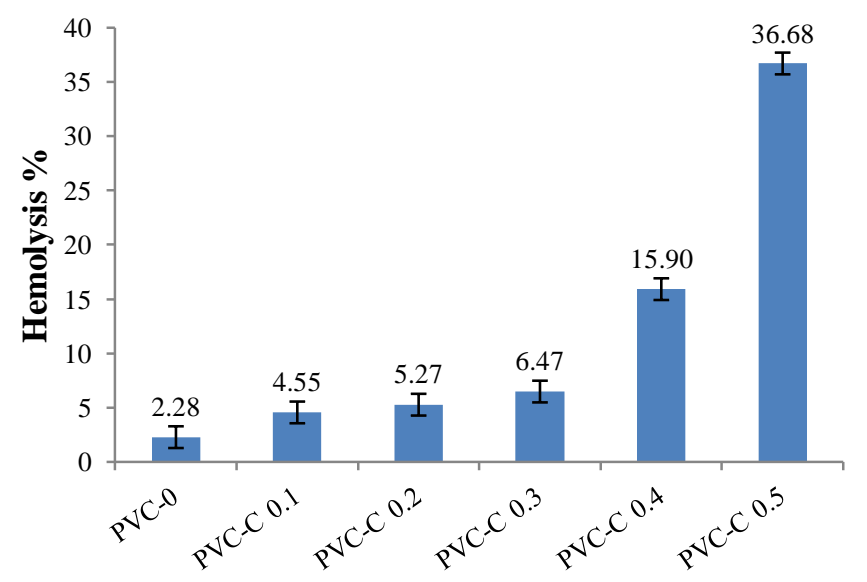

Fig. 10: Hemolysis percentage of neat $\mathrm{PVC}$ and that plasticized ith different amounts of clove oil

\section{Thrombogenicity}

As the membrane is designed to be used topically in contact with blood, it is important to evaluate its tissue and blood compatibility. Furthermore, the thrombogenic character is a desirable property in membranes. Figure 11 shows the weights of blood clots obtained on thrombogenicity test. It was observed that clot formation is higher in the plasticized compare with neat PVC membranes than in the control so; the polymers are classified as thrombogenic.

This characteristic is directly related to the hydrophilicity of the materials. When placed in contact with a hydrophobic surface, proteins adsorb to it in a strong and irreversible way, while at hydrophilic surfaces proteins adsorb weakly and reversibly (Abdou and Hassan, 2014). This relation between hydrophilicity and thrombosis was confirmed by the higher value of thrombus weight that was formed when blood contacted with PVC membranes, and that will increase by clove oil percent as a 
direct result of an increase in hydrophobicity. Finally, the prepared membranes should be applied on an animal model for more investigations.

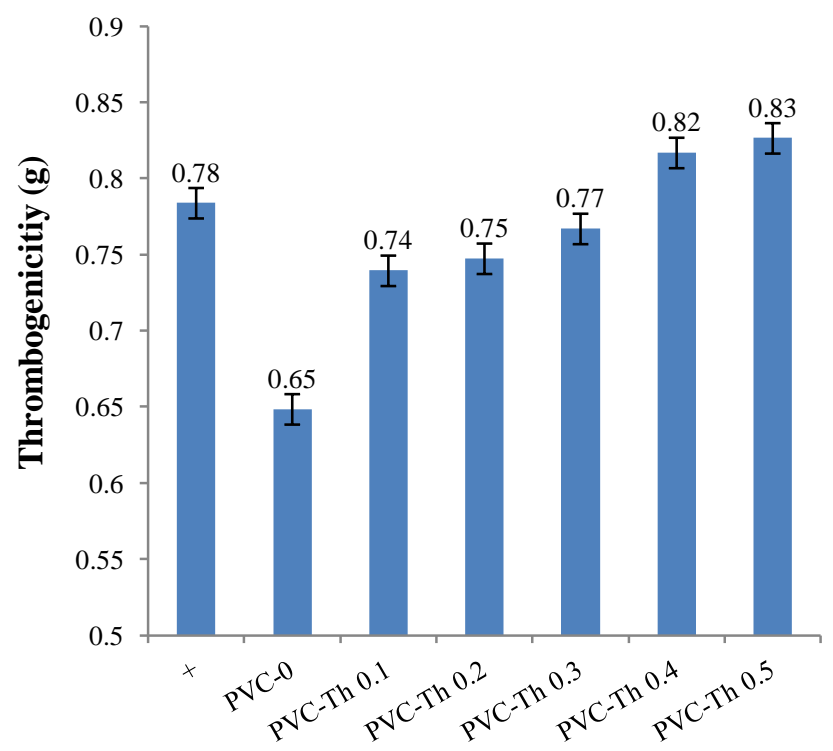

Fig. 11: Thrombogenicity of neat $P V C$ and that plasticized ith different amount of clove oil.

\section{CONCLUSION}

PVC membranes plasticized with clove oil were prepared and characterized. The Results showed improvement in physical and mechanical properties of the membranes. Additionally, Bioevaluation study showed increasing of antibacterial activities against both Gram-positive and Gram-negative bacteria with increasing of clove oil concentrations within membranes. On the other hand, there are prominently increase in blood hemolysis and thrombus weight. This study should be subjected to further analysis and investigations to obtain a good PVC membrane with potent features to apply in blood bags manufacture.

\section{REFERENCES}

Abdou H, Hassan MA. Protective Role of Omega-3 Polyunsaturated Fatty Acid against Lead Acetate-Induced Toxicity in Liver and Kidney of Female Rats. Biomed Research International Journal, 2014; doi.org/10.1155/2014/435857

Allwood MC. The release of phthalate ester plasticizer from intravenous administration sets into fat emulsion. Int J Pharm, 1986; 29:233-236.

Asadinezhad A, Novák I, Lehocký M, Bílek F, Vesel A, Junkar I. Polysaccharides coatings on medical-grade PVC: A probe into surface characteristics and the extent of bacterial adhesion. Molecules, 2010; 15: $1007-1027$.

ASTM International (2012): Complete Standard Terminology Relating to Plastics. Available at: (http://www.astm.org/ Standards/D883.htm).

Bacaloglu R, Fisch MH. Degradation and stabilization of poly(vinyl chloride) II. Kinetics of the thermal degradation of poly(vinyl chloride). Polym. Degrad. Stab, 1994; 45: 325-333.

Balakrishnana B, Kumarb DS, Yoshidab Y, Jayakrishnan A.Jayakrishnan. Chemical modification of poly (vinyl chloride) resin using poly (ethylene glycol) to improve blood compatibility. Biomaterials, 2005; 26 (17): 3495-3502.

Balazs DJ, Triandafillu K, Wood P, Chevolot Y, Delden CV, Harms H, Hollenstein C, Mathieu HJ. Inhibition of bacterial adhesion on PVC endotracheal tubes by RF-oxygen glow discharge, sodium hydroxide and silver nitrate treatments.Biomaterials, 2004; 25 (11):2139-51.

Brash J, Horbett T. "Proteins at interfaces: current issues and future prospects", in: Proteins at interfaces II, 1995, 1-23, Horbett T. and Brash J (Eds.), ASC Symposium Series 602, Washington DC.

Brewer RH. The influence of the orientation, roughness, and wettability of solid surfaces on the behavior and attachment of planulae of cyanea (Cnidaria: Scyphozoa), Biol. Bull, 1984; 166:11-21.

Burt SA. Essential oils: Their antibacterial properties and potential applications in foods - a review. Int. J. Food Microbiol, 2004; 94: 223-253.

Castro MP, Palavecino NZ, Herman C, Garro OA, Campos CA. Lactic acid bacteria isolated from artisanal dry sausages: Characterization of antibacterial compounds and study of the factors affecting bacteriocin production. Meat Science, 2011; 87: 321-329.

Chae SR, Wang S, Hendren ZD, Wiesner MR, Watanabe Y, Gunsch CK. Effects of fullerene nanoparticles on Escherichia coli K12 respiratory activity in aqueous suspension and potential use for membrane biofouling control, J. Membr. Sci. (2008).

Changsheng Z, Xiangdong L, Motoyoshi N, Norio N. Blood compatible aspects of DNA-modified polysulfone membrane, protein adsorption and platelet adhesion. Biomaterials, 2003; 24: 3747-3755.

Chapman J, Lawlora A, Weirb E, Quiltyb B, Regana F. Phthalate doped PVC membranes for the inhibition of fouling. Journal of Membrane Science, 2010; 365: 180-187.

Chinn J, Posso S, Horbett T, Ratner B. "Postadsorptive transitions in fibrinogen adsorbed to polyurethanes: changes in antibody binding and sodium dodecyl sulfate elutability", J. Biomed. Mater. Res, 1992; 26: 757-78.

Duran-Jorda F. The Barcelona Blood-Transfusion Service. Lancet, 1939; 233: 773-776

Folarin OM, Sadiku ER. Thermal stabilizers for poly(vinyl chloride): A review International Journal of the Physical Sciences, 2011; 6(18): 4323-4330.

Greening DW, Glenister KM, Sparrow RL, Simpson RJ. Joint Proteomics Laboratory, Ludwig Institute for Cancer Research \& The Walter and Eliza Hall Institute of Medical Research, Royal Melbourne Hospital, Parkville, Victoria, Australia. J Proteomics, 2010; 73: 386-395.

Guess WL, Austin J, Jacob J. A Study of Polyvinyl Chloride Blood Bag Assemblies, I: Alteration or Contamination of ACD Solutions. Ann Pharmacother, 1967; 1:120-7.

Hassan MA, Amara AA, Abuelhamd AT, Haroun BM. Leucocytes show improvement growth on PHA polymer surface. Pakistan Journal of Pharmaceutical Science, 2010; 23: 332-336.

Herrero M, Reinecke H, Mijangos C. Controlled wet chemical modification and bacterial adhesión on PVC surface. Polym. Degrad. Stabil, 2006; 91: 1915-1918.

Imai Y, Nose YJ. New method for evaluation of antithrombogenicity of materials, Biomed. Mater, Res, 1972; 6: 165-172. 2(7676):778.

Jaeger RJ, Rubin RJ. Plasticisers from P.V.C. The Lancet, 1970,

Loff S, Kabs F, Witt K, Sartoris J, Mandl B, Niessen KH, Waag KL. Polyvinylchloride infusion lines expose infants to large amounts of toxic plasticizers. J. Pediatr. Surg, 2000; 35: 1775-1781.

Mao C, Zhao WB, Zhu AP, Shen J, Lin SC. A photochemical method for the surface modification of poly(vinyl chloride) with Obutyrylchitosan to improve blood compatibility,2004; 39 (9):1151-1157.

McNeill IC, Memetea L, Cole WJ. A study of the products of PVC thermal degradation. Polym. Degrad. Stab, 1995; 49: 181 $-191$.

Mohy Eldin MS, Hashem AI, Omer AM, Tamer TM. Wound dressing membranes based on chitosan: Preparation, characterization and biomedical evaluation. International Journal of Advanced Research, 2015a; 3 (8): 908- 922. 
Mohy Eldin MS, Soliman EA, Hashem AI, Tamer TM. Chitosan Modified Membranes for Wound Dressing Applications: Preparations, Characterization and Bio-Evaluation. Trends Biomater. Artif. Organs, 2008; 22: 154-164.

Mohyeldin MS, Tamer MT, Abusaid MA, Soliman EA, Madi NK, Ragab I, Fadel I. Grafting of Chitosan onto PVC Surfaces for Biomedical Applications. Advances in Polymer Technology, 2015b, DOI 10.1002/adv.21640 C

Norde W, Lyklema J. Why proteins prefer interfaces. J. Biomater. Sci. Polymer Ed, 1991; 2: 183-202.

Norde W. Adsorption of proteins from solution at the solidliquid interface", Adv Colloid Interface Sci, 1986; 25: 267-340.

Omer AM , Tamer MT, Hassan M A, Sabet M M, Mohy Eldin M S. Plasticization of PVC membranes with eugenol for Biomedical Applications. Int J Pharm 2016; 6(1): 149-155

Oussalah M, Caillet S, Saucier L, Lacroix M. Antimicrobial effects of selected plant essential oils on the growth of a pseudomonas putida strain isolated from meat. Meat Sci, 2006;73: 236-44.

Rahman M, and Brazel, C.S. The Plasticizer Market: An Assessment of Traditional Plasticizers and Research Trends to Meet New Challenges, Prog. Polym. Sci, 2004; 29: 1223-1248

Ramsey G, Schmidt PJ. Transfusion Medicine in Chicago, before and after the "Blood Bank". Transfus Med Rev, 2009;23:310-321.

Sharififar F, Moshafi MH, Mansouri SH, Khodashenas M, Khoshnoodi M. In vitro evaluation of antibacterial and antioxidant activities of the essential oil and methanol extract of endemic Zataria multiflora Boiss. Food Control, 2007;7:800-5.
Simon P. Kinetics of polymer degradation involving the splitting off of small molecules: Part VII- Thermo-oxidative dehydrochlorination of PVC. Polym Degrad. Stab, 1992; 36: 85-89.

Skyttä E, Mattila ST. A quantitative method for assessing bacteriocins and other food antimicrobials by automated turbidometry. Journal of Microbiological Methods, 1991;14: 77-88.

Tickner JA, Schettler T, Guidotti T, McCally M, Rossi M. Health risks posed by use of Di-2-ethylhexyl phthalate (DEHP) in PVC medical devices: a critical review. Am. J. Ind. Med, 2001; 39: 100-111.

US Pharmacopeia XXIII. US Pharmacopeial Convention, Rockville, MD, 1994: 119.

Vogler E.. Structure and reactivity of water at biomaterial surfaces", Adv. Colloid Interface Sci, 1998; 74: 69-117.

Vroman L, Adams A. Identification of rapid changes at plasmasolid interfaces. J. Biomed. Mater. Res, 1969; 3:43-67.

Zhou ZR and Meyerhoff ME. Preparation and Characterization of Polymeric Coatings with Combined Nitric Oxide Release and Immobilized Active Heparin, Biomaterials, 2005; 26(33): 6506-6517.

\section{How to cite this article:}

Omer AM, Tamer TM, Monem AR, Elmoaty SA, El-Fatah MA, Saad GR. Development of PVC membranes with clove oil as plasticizer for blood bag applications. J App Pharm Sci, 2016; 6 (07): 085-093. 